Original Research

\title{
Novel Long-Acting Progesterone Protocols Used to Successfully Synchronize Donor and Recipient Mares With Satisfactory Pregnancy and Pregnancy Loss Rates
}

\author{
Gabriel M. Greco ${ }^{\text {a }}$, Eduardo G. Fioratti ${ }^{a}$, Lorenzo G. Segabinazzi ${ }^{\text {, }}$, José A. Dell'Aqua Jr. ${ }^{\text {a }}$, \\ André M. Crespilho ${ }^{\mathrm{b}}$, Maria Manoela B. Castro-Chaves ${ }^{\mathrm{a}}$, Marco Antonio Alvarenga ${ }^{\mathrm{a}, *}$ \\ a Department of Animal Reproduction and Veterinary Radiology, São Paulo State University, UNESP, Botucatu, Brazil \\ ${ }^{\mathrm{b}}$ UNISA, São Paulo, Brazil
}

\section{A R T I C L E I N F O}

\section{Article history:}

Received 12 January 2015

Received in revised form 24 April 2015

Accepted 24 July 2015

Available online 6 August 2015

\section{Keywords:}

Recipient mare

Progesterone protocol

Embryo transfer

\begin{abstract}
A B S T R A C T
The present study aimed to evaluate pregnancy and pregnancy loss rates of recipients treated with alternative long-acting progesterone protocols, designed to synchronize acyclic and cyclic mares, regardless of their cycle phase. A total of 150 Campolina breed mares were used as recipients. Recipient mares were assigned to six different groups with 25 animals each. Groups 1 to 5 were treated with progesterone at some point. Group 1 (acyclic recipients); group 2 (cyclic estrous recipients with one $\geq 35 \mathrm{~mm}$ follicle); group 3 (cyclic estrous recipients with an anovulatory follicle); group 4 (early estrous cyclic recipients); group 5 (diestrous cyclic recipients), and group 6 (cyclic recipients-control). Embryos (day 8) were transferred 4 days after ovulation or 4 days after progesterone injection. Pregnant diagnosis was performed by transrectal ultrasonography 1 week after embryo transfer. Pregnant recipients were evaluated for possible losses and mares treated every 14 days with $3 \mathrm{~g}$ (intramuscular) of long-acting progesterone, until 120 days of pregnancy. Pregnancy at 15 days and pregnancy loss rates were recorded and statistically evaluated through multivariate regression $(P<.05)$. Pregnancy and pregnancy loss rates were similar within groups (G1: $76 \%-10.5 \%$; G2: 76\%-5.9\%; G3: $56 \%-0 \%$; G4: $80 \%-10 \%$; G5: $60.9 \%-0 \%$; and G6: 60\%-13.3\%). In conclusion, the novel long-acting progesterone protocols proposed in this study allowed successfully the utilization of mares with asynchronous cyclic as embryo recipients, serving as an alternative specially when few recipients are available and usual synchronization is not possible.
\end{abstract}

(c) 2016 Elsevier Inc. All rights reserved.

\section{Introduction}

Equine embryo transfer (ET) has been routinely conducted especially in Brazil and Argentina, which are responsible for $50 \%$ of all transferred embryos around the world [1]. It is known that the selection and management

\footnotetext{
* Corresponding author at: Marco Antonio Alvarenga, Departamento de Reprodução Animal e Radiologia Veterinária, FMVZ, UNESP, Distrito de Rubião Junior, s/nº, 18618-970 Botucatu, São Paulo, Brazil.

E-mail address: malvarenga@fmvz.unesp.br (M.A. Alvarenga).
}

of recipient mares are the most important factors affecting pregnancy and embryonic loss rates in ET programs [2]. Therefore, better results are usually achieved when high numbers of recipients are available.

Synchrony between donor and recipient is needed for pregnancy establishment after an ET procedure [3]. However, at the beginning and the end of the breeding season, the percentage of recipients showing normal estrous cycles is lower than donors. During these periods, it is not uncommon to evaluate recipients in anestrous/ transitional phase or with ovulatory failure, developing hemorrhagic anovulatory follicles. 
Progestin treatment allows the use of ovariectomized or acyclic recipients with satisfactory pregnancy and embryonic loss rates [4,5]. In the past few years, longacting progesterone compounds have been widely used in Brazil [6,7] and Argentina [8]. Acyclic recipient mares are treated every 7 or 14 days, respectively, with either $1.5 \mathrm{~g}$ of progesterone or $3.0 \mathrm{~g}$ of progesterone of a longacting progesterone formulation containing $300 \mathrm{mg} / \mathrm{mL}$ of progesterone (P4LA300) until pregnancies reach about 120 days of age [9].

The optimal recipient-to-donor ratio is rarely available with the ongoing increase of equine ET in Brazil, even during the breeding season, impairing proper synchronization, and lowering pregnancy rates. The present study aimed to evaluate pregnancy and pregnancy loss rates of recipient mares treated with alternative long-acting progesterone protocols, designed to successfully synchronization between acyclic and cyclic mares, regardless of their estrous phase.

\section{Material and Methods}

This experiment was conducted in the 2013/2014 breeding season. A total of 148 ETs were performed ( 87 in farm $A$ and 61 in farm B) in two stud farms located in Conselheiro Lafaiete (latitude $20^{\circ} 40^{\prime} \mathrm{S}$ and longitude $\left.43^{\circ} 48^{\prime} \mathrm{W}\right)$, Minas Gerais state, Brazil. One hundred fifty Campolina breed mares, aged 3 to 10 years ( \pm 7.4 years), weighing 450 to $600 \mathrm{~kg}$, remaining in similar management and pastures, receiving $2.0 \mathrm{~kg}$ of concentrated balanced grain, water, and mineral salt ad libitum, and showing a body condition score from 6.0 to 8.0 ( \pm 7.0$)$ according to Henneke et al [10], were used as recipients. Most of these mares produced a foal 1 year before the experimental breeding season. These animals were evaluated at 7-day intervals by rectal palpation and ultrasonography, using a 5.0-MHz linear transducer (Chison V8300-China), and classified as acyclic or cyclic according to their reproductive status by only one veterinarian. Acyclic mares were palpates at least two times before the start of the treatment at 7-day intervals with no corpus luteum being observed. Mares used in this study did not show any reproductive abnormalities through ultrasonography and were negative for endometrial inflammation after cytologic evaluation [11].

Donor mares aged 8 to 18 years were used and were evaluated three times for a week. When one $\geq 35 \mathrm{~mm}$ follicle and at least grade 2 endometrial edema [12] were found, ovulation induction was performed with intramuscular (IM) injection of $750 \mu \mathrm{g}$ using deslorelin acetate (Sincrorelin, Ouro Fino, Brazil). Inseminations were processed 24 hours after induction of the ovulation with fresh semen (doses containing $500 \times 10^{6}$ viability spermatozoa) from two stallions of known fertility. Eight-day embryos were recovered by the nonsurgical technique using transcervically catheter (Bullet tip 28FR, Pets-Inc, TX, USA) connected to $0.75-\mu \mathrm{m}$ embryo filter (WTA, Brazil). Flushes were conducted with lactated Ringer solution prewarmed to $36^{\circ} \mathrm{C}$. Embryos were washed in 10 drops of a holding media (Botu-Embryo, Botupharma, Brazil) and maintained at room temperature until 1 hour after flushing. Embryos were classified as development stage and viability according to McKinnon and Squires [13]. Embryos in appropriate development stage and good viability (grades 1 and 2) were transferred to recipients using nonsurgical technique 4 days after ovulation (D4) [5,14-17] in control group or 4 days after treatment with P4LA300 (BioRelease LAP4300, BetLabs, Lexington, KY, USA) in all the other groups. Embryos were transferred by only one veterinarian. Progesterone-treated recipients received another $1.5 \mathrm{~g}$ (IM) of P4LA300 on day of ET. Pregnant diagnosis was performed by ultrasonography 1 week after transfer and monitoring at 15-day interval up to 120 days of pregnancy. Pregnant recipients under progesterone treatment were treated every 14 days with $3 \mathrm{~g}$ (IM) of P4LA300 until fetuses reached 120 days of age.

\subsection{Groups}

Mares were divided into the six following groups, containing 25 animals each, according to the description given in the following paragraphs.

\subsubsection{Group 1: Acyclic Recipients}

Acyclic recipients that showed at least grade 2 endometrial edema [12] after 2 days of treatment with $5.0 \mathrm{mg}$ (IM) of estradiol benzoate (Estrogin, Farmavet, São Paulo, Brazil) were treated with $1.5 \mathrm{~g}$ (IM) of P4LA300. Mares that not show edema after estradiol benzoate were not used.

\subsubsection{Group 2: Cyclic Estrous Recipients With One $\geq 35 \mathrm{~mm}$ Follicle}

Cyclic estrous recipients that showed one $\geq 35 \mathrm{~mm}$ follicle and at least grade 2 endometrial edema [12] were simultaneously treated with 2.000 IU (IV) of human chorionic gonadotropin (hCG) (Chorulon, Intervet International B.V., Boxmeer, the Netherlands) and $1.5 \mathrm{~g}$ (IM) of P4LA300, aiming induce ovulation. In this case, ET was performed 4 days after P4LA300 injection. Progesterone injections were discontinued if corpus luteum was observed by ultrasonography on the day at ET.

\subsubsection{Group 3: Cyclic Estrous Recipients With an Anovulatory Follicle \\ Cyclic estrous recipients that developed a hemorrhagic anovulatory follicle 48 hours after ovulation induction with hCG and still showing a minimal degree of endometrial edema received $1.5 \mathrm{~g}$ (IM) of P4LA300. Hemorrhagic follicle was characterized by the increase in the follicular size which fails to rupture in association with the observation of echogenic specks that float freely in the follicular fluid, with subsequent luteinization of the follicular wall in most occasions [18-20].}

\subsubsection{Group 4: Early Estrous Cyclic Recipients}

Cyclic mares in early estrous and showing at least grade 2 endometrial edema and only follicles $\leq 35 \mathrm{~mm}$ were treated with $1.5 \mathrm{~g}$ (IM) of P4LA300.

\subsubsection{Group 5: Diestrous Cyclic Recipients}

Cyclic diestrous recipients from 5 (D5) to 14 days after ovulation (D14), showing no endometrial edema, good uterine tone, and a visible corpus luteum in one of their 
ovaries, were simultaneously treated (IM) with $5.0 \mathrm{mg}$ of estradiol benzoate and $5.0 \mathrm{mg}$ of dinoprost tromethamine (Lutalyse, Pfizer, São Paulo, Brazil). If at least grade 2 endometrial edema [12] was detected 2 days after treatment, $1.5 \mathrm{~g}$ (IM) of P4LA300 was administered. Mares that not followed this criteria were not used.

\subsubsection{Group 6: Cyclic Recipients (Control)}

Cyclic recipients showing at least grade 2 endometrial edema and one $\geq 35 \mathrm{~mm}$ follicle had their ovulations induced with 2.000 IU (IV) of hCG were used as control.

\subsection{Statistical Analysis}

Pregnancy rates and pregnancy loss rates were analyzed by multivariate regression analysis using Biostat 3.0 (Mamirauá Institute, Brazil) and were considered as binary variables. The experimental groups and effect of farms as well as their interactions were considered predictive variables. The results are assumed that differences are significant when $P<.05$.

\section{Results}

There was not individual farms effect or treatment effect $(P>.05)$ for pregnancy rates and pregnancy loss rates in this study.

Pregnancy rates and pregnancy loss rates (up to 120 days of gestation) were similar $(P>.05)$ between groups, as showed in Table 1.

From 29 acyclic mares (group 1) and 25 diestrous mares (group 5), four and two mares, respectively, no endometrial edema was observed after estradiol benzoate treatment, therefore not being subjected to progesterone treatment or ET.

From seven pregnancy loses, three occurred before 45 days and four after 45 days of gestation $(P>.05)$.

In group $2,72.0 \%(18 / 25)$ of the mares showed a corpus luteum at the day of transfer and $28.0 \%$ (7/25) mares that

Table 1

Pregnancy and pregnancy loss rates in recipient mares after treatment with long-acting progesterone hormonal regimens.

\begin{tabular}{llr}
\hline Evaluated Group & Pregnancy Rate (\%) & Pregnancy Loss Rate (\%) \\
\hline Group 1 & $76.0(19 / 25)$ & $10.5(2 / 19)$ \\
Group 2 & $76.0(19 / 25)$ & $5.9(1 / 17)$ \\
Group 3 & $56.0(14 / 25)$ & $0(0 / 14)$ \\
Group 4 & $80.0(20 / 25)$ & $10.0(2 / 20)$ \\
Group 5 & $60.9(14 / 23)$ & $0(0 / 14)$ \\
Group 6 (control) & $60.0(15 / 25)$ & $13.3(2 / 15)$ \\
\hline
\end{tabular}

Group 1 (acyclic recipients) $1.5 \mathrm{~g}$ of P4LA (long-acting progesterone) was injected after 2 days of treatment with $5.0 \mathrm{mg}$ of estradiol benzoate; group 2 (cyclic estrous recipients with one $\geq 35 \mathrm{~mm}$ follicle) simultaneously treated with $2.000 \mathrm{IU}$ of human chorionic gonadotropin (hCG) and $1.5 \mathrm{~g}$ of P4LA; group 3 (cyclic estrous recipients with an anovulatory follicle) 48 hours after ovulation induction with hCG treated with $1.5 \mathrm{~g}$ of P4LA; group 4 (early estrous cyclic recipients) treated with $1.5 \mathrm{~g}$ of P4LA; group 5 (diestrous cyclic recipients) treated with $5.0 \mathrm{mg}$ of estradiol benzoate and $5.0 \mathrm{mg}$ of dinoprost tromethamine, 2 days after this treatment, $1.5 \mathrm{~g}$ of P4LA was administered; group 6 (cyclic recipients-control), pregnant recipients under progesterone treatment were treated every 14 days with $3 \mathrm{~g}$ of P4LA until 120 days of pregnancy. did not ovulate. Similar pregnancy rates and pregnancy loss rates $(P>.05)$ were obtained in ovulated and nonovulated recipients in group 2 , as showed in Table 2 .

Ovulations were detected 2 days after treatment in $61.1 \%$ of the mares $(11 / 18)$ and 3 days after treatment in the remaining recipients (38.9\%; $7 / 18$ ).

\section{Discussion}

It has been demonstrated in the present study that progesterone-treated acyclic and cyclic recipients in different phases of the estrus cycle can be used with satisfactory pregnancy and pregnancy loss rates, as showed in others studies with recipient mares treated with long-acting progesterone [6,21-25] and similar to those obtained with cyclic recipients [5-7]. Usually, acyclic recipients are pretreated with estrogen compounds, which act in the development of endometrial edema before progesterone. With that in mind, we hypothesized that the presence of moderate endometrial edema in cycling mares was enough to indicate that the recipient was suitable for progesterone treatment and ET a couple days later.

The range on pregnancy rate obtained in all groups (56\%-80\%) did not differ from what has been reported for either cyclic recipients of 70\% [2], 82.9\% [26], 67.8\% [5], and $82.5 \%$ [15] or progestin-treated acyclic recipients of $55.6 \%$ [5] and 75.9\% [6]. On the other hand, for progesteronetreated ET recipients, the range of pregnancy loss rates at day $120(0 \%-10.5 \%)$ was lower than the ones reported at day 50, by Carnevale et al [5] and Rocha Filho et al [6] when noncycling recipient mares were used.

We have identified advantages and disadvantages of treating recipients with long-acting progesterone. The most important advantage is the possibility to transfer embryos from donor mares that most of time started to cycle 2 months before and stop to cycle 2 months after the recipient mares, and another advantage is the possibility of increasing the number of available recipient when using cycling recipient mares even in estrus or diestrus. As disadvantage, we can highlight the cost associated with hormonal administrations, which can also be time consuming because pregnant mares must receive long action P4 every 14 days until pregnancies reach 120 days of age and local inflammatory reaction caused by injections. This problem can be overcome with the use of cyclic or asynchronous recipient mares at the end of estrus, as used in group 2, where the most of mares can ovulate and form a normal corpus luteum.

Group 2 was composed of cyclic mares showing one $\geq 35 \mathrm{~mm}$ follicle and endometrial edema, simultaneously treated with $2.000 \mathrm{IU}$ (IV) of hCG and $1.5 \mathrm{~g}$ (IM) of P4LA300.

\section{Table 2}

Pregnancy and pregnancy loss rates in ovulated and nonovulated cyclic estrous recipients with one $\geq 35 \mathrm{~mm}$ follicle simultaneously treated with hCG and long-acting progesterone (group 2).

\begin{tabular}{llc}
\hline Variable & Pregnancy Rate $(\%)$ & Pregnancy Loss Rate $(\%)$ \\
\hline Ovulated & $72.2(13 / 18)$ & $7.7(1 / 13)$ \\
Not ovulated & $57.1(4 / 7)$ & $0(0 / 7)$ \\
\hline
\end{tabular}

Abbreviation: hCG, human chorionic gonadotropin. 
A corpus luteum was detected at ET in $72.0 \%$ of these mares. Canisso et al [27] using intravaginal progesterone implant or oral altrenogest both for 2 days observed that neither of these treatments delayed ovulation. Although we did not measure progesterone concentrations to confirm luteal competence, we assume they secreted enough progesterone to maintain pregnancies because only 1 of the 13 mares that developed a corpus luteum lost their pregnancies, despite interrupting progesterone treatment on ovulation detection. These findings lead us to conclude that it is possible to use recipients as early as D1 and D2 after ovulation when mares were treated with progesterone on the day of ovulation induction. Similar pregnancy rates were obtained by Caiado et al [24], where in their work, recipients received embryos at D2 and daily injected with $200 \mathrm{mg}$ of short-acting progesterone (IM) beginning at the day of ovulation (D0) until D5.

It has been previously shown that there is a delay of production of progesterone by the hemorrhagic anovulatory [28]. In this regard, we administered progesterone to mares with hemorrhagic anovulatory follicles and they were used only with a minimal grade of endometrial edema still present, to avoid ET to asynchronous uterine environment.

\section{Conclusions}

In conclusion, the novel long-acting progesterone protocols proposed in the present study allowed successfully the utilization of mares with asynchronous cyclic as embryo recipients.

\section{References}

[1] Losinno L, Alvarenga MA. Critical factors in equine embryo transfer programmes in Brazil and Argentina. Acta Sci Vet 2006;25:39-49. Portuguese.

[2] Squires EL, McCue PM, Vanderwall D. The current status of equine embryo transfer. Theriogenology 1999;51:91-104.

[3] McKinnon AO, Squires EL, Voss JL, Cook VM. Equine embryo transfer: a review. Compend Contin Educ Vet 1988;10:343-55.

[4] Hinrichs K, Sertich PL, Cummings MR, Kenney RM. Pregnancy in ovariectomized mares achieved by embryo transfer: a preliminary study. Equine Vet J Suppl 1985;3:74-5.

[5] Carnevale EM, Ramirez RJ, Squires EL, Alvarenga MA, Vanderwall DK, McCue PM. Factors affecting pregnancy rates and early embryonic death after equine embryo transfer. Theriogenology 2000;54:965-79.

[6] Rocha Filho AN, Pessôa MA, Gioso MM, Alvarenga MA. Transfer of equine embryos into anovulatory recipients supplemented with short or long acting progesterone. Anim Reprod Sci 2004;1:91-5.

[7] Greco GM, Avanzi BR, Fioratti EG, Queiroz FJR, Meira C, Alvarenga MA. Effect of interrupting progesterone administration to pregnant acyclic recipient mares showing the development of supplementary corpora lutea. Proceedings of the 7th International Symposium on
Equine Embryo Transfer; 2008 Jul 9-11; Cambridge, UK. Newmarket: R \& W Communications; 2008.

[8] Riera FL, Roldán JE, Hinrichs K. Pregnancy rate after embryo transfer in ovulating versus progesterone treated-anestrous recipient mares in a commercial embryo transfer programme. Proceedings of the 7th International Symposium on Equine Embryo Transfer; $2008 \mathrm{Ju}$ 9-11; Cambridge, UK. Newmarket: R \& W Communications; 2008.

[9] Greco GM, Dell'aqua Jr JA, Alvarenga MA. Pregnancy and pregnancy loss rates of acyclic recipient mares treated with two different longacting progesterone concentrations. Reprod Fertil Dev 2010;22:246.

[10] Henneke DR, Potter GD, Kreider JL, Yeates BF. Relationship between condition score, physical measurement, and body fat percentage in mares. Equine Vet J 1983;15:371-2.

[11] Alvarenga MA, Iwana De Matos MC. Utilização da escova ginecológica cytobrush na coleta de material endometrial de éguas. Arq Bras Med Vet Zootec V 1990;42:67-8.

[12] Samper JC. Induction of estrous and ovulation: why some mares respond and others do not. Theriogenology 2008;70:445-7.

[13] McKinnon AO, Squires EL. Morphologic assessment of the equine embryo. J Am Vet Med Assoc 1988;192:401-6.

[14] Caiado JRC, Fonseca FA, Silva JFS, Fontes RS, Caiado JCC. Application of flunixin meglumine before non-surgical embryo transfer in Mangalarga Marchador mares. Rev Bras de Ciências Veterinárias 2005; $12: 11-5$.

[15] Jasko DJ. Comparison of pregnancy rates following nonsurgical transfer of day 8 equine embryos using various transfer devices. Theriogenology 2002;58:713-5.

[16] Squires EL, Carnevale EM, Mccue PM, Bruemmer JE. Embryo technologies in the horse. Theriogenology 2003;59:151-70.

[17] Jacob JCF, Santos GO, Oliveira JP, Gastal MO, Gastal EL. Evaluation of reproductive parameters in a commercial equine embryo transfer program. Anim Reprod Sci 2010;121:305-6.

[18] McCue PM, Squires EL. Persistent anovulatory follicles in the mare. Theriogenology 2002;58:541-3.

[19] Ginther OJ, Gastal EL, Gastal MO, Beg MA. Incidence. endocrinology, vascularity, and morphology of haemorrhagic anovulatory follicles in mares. J Equine Vet Sci 2007;27:130-9.

[20] Cuervo-Arango J, Newcombe JR. The effect of hormone treatments (hCG and cloprostenol) and season on the incidence of hemorrhagic anovulatory follicles in the mare: a field study. Theriogenology 2009;72:1262-7.

[21] Carnevale EM, Coutinho da Silva MA, Panzani D, Stokes JE, Squires EL. Factors affecting the success of oocyte transfer in a clinical program for subfertile mares. Theriogenology 2005;64: 519-27.

[22] Testa AC, Carmo MT, Alvarenga MA. Perda embrionária precoce em éguas receptoras de embrião em anestro tratadas com progesterona de longa ação. Acta Sci Vet 2005;33:198-200.

[23] Stout TAE. Equine embryo transfer: review of developing potential. Equine Vet J 2006;38:467-78.

[24] Caiado JRC, Fonseca FA, Silva JFS, Fontes RS. Hormonal treatment of recipient mares of the Mangalarga Marchador breed for embryo transfer on the second day post ovulation. Braz J Anim Sci 2007;36: 360-8. Portuguese.

[25] Kaercher F, Kozicki LE, Camargo CE, Weiss RR, Santos IW, Muradas PR, Bertol MAF, Abreu RA. Embryo transfer in anovulatory recipient mares treated with estradiol benzoate and long-action progesterone. J Equine Vet Sci 2013;33:205-9.

[26] Foss R, Wirth N, Schiltz P, Jones J. Nonsurgical embryo transfer in a private practice (1998). Am Assoc Equine Pract 1999;45:210-2.

[27] Canisso IF, Gallacher K, Gilbert M, Korn A, Schweizer CM, BedfordGuaus SJ, Gilbert RO. Preovulatory progestagen treatment in mares fails to delay ovulation. Vet J 2013;197:324-8.

[28] Ginther OJ, Gastal EL, Gastal MO, Beg MA. Conversion of a viable preovulatory follicle into a hemorrhagic anovulatory follicle in mares. Anim Reprod Sci 2006;3:29-40. 